\title{
Communication
}

\section{Mycobiota and Aflatoxin B1 in Feed for Farmed Sea Bass (Dicentrarchus labrax)}

\author{
Inês Filipa Martins Almeida ${ }^{1}$, Hermínia Marina Lourdes Martins ${ }^{2, *}$, \\ Sara Maria Oliveira Santos ${ }^{2}$, Maria Suzana Freitas ${ }^{1}$, José Manuel Gaspar Nunes da Costa ${ }^{1}$ \\ and Fernando Manuel d'Almeida Bernardo ${ }^{3}$
}

1 Direcção Geral de Veterinária, Largo da Academia Nacional de Belas Artes, no 2, 1249-105 Lisboa, Portugal; E-Mails: ines.almeida@dgv.min-agricultura.pt (I.F.M.A.); susana.freitas@dgv.min-agricultura.pt (M.S.F.); josecosta@dgv.min-agricultura.pt (J.M.G.N.C.) INRB, I.P., Laboratório Nacional de Investigação Veterinária, Serviço de Micologia, Estrada de Benfica 701, 1549-011 Lisboa, Portugal; E-Mail: sarasantos441@hotmail.com

3 UTL, Faculdade de Medicina Veterinária, CIISA-Pólo Universitário Rua Prof.Cid Santos, Alto da Ajuda, 1300-417 Lisboa, Portugal; E-Mail: fbernardo@fmv.utl.pt

* Author to whom correspondence should be addressed; E-Mail: marina.martins@lniv.min-agricultura.pt; Tel.: 003512171153 36; Fax: 00351217115384.

Received: 10 December 2010; in revised from: 10 January 2011 / Accepted: 18 February 2011 / Published: 25 February 2011

Abstract: The safety characteristics of feed used in fish and crustacean aquaculture systems are an essential tool to assure the productivity of those animal exploitations. Safety of feed may be affected by different hazards, including biological and chemical groups. The aim of this preliminary study was to evaluate fungi contamination and the presence of aflatoxins in 87 samples of feed for sea bass, collected in Portugal. Molds were found in 35 samples (40.2\%) in levels ranging from 1 to $3.3 \log 10 \mathrm{CFU} \cdot \mathrm{g}^{-1}$. Six genera of molds were found. Aspergillus flavus was the most frequent, found in all positive samples, with a range from 2 to $3.2 \log _{10} \mathrm{CFU} \cdot \mathrm{g}^{-1}$. Aspergillus niger was found in 34 samples (39.1\%), ranging from 1 to $2.7 \log _{10} \mathrm{CFU} \cdot \mathrm{g}^{-1}$. Aspergillus glaucus was found in 26 samples (29.9\%) with levels between 1 and $2.4 \log _{10} \mathrm{CFU} \cdot \mathrm{g}^{-1}$. Penicillium spp. and Cladosporium spp. were both found in 25 samples (28.7\%). Fusarium spp. was found in 22 samples (25.3\%), ranging from 1 to $2.3 \log _{10} \mathrm{CFU} \cdot \mathrm{g}^{-1}$. All feed samples were screened for aflatoxins using a HPLC technique, with a detection limit of $1.0 \mu \mathrm{g} \cdot \mathrm{kg}^{-1}$. All samples were aflatoxin negative. 
Keywords: aquaculture; fungi; fish feed; safety control

\section{Introduction}

Nowadays, aquaculture is one of the most important animal husbandry systems, allowing a consistent growth of $1 \%$ per year in the last three decades all over the world. This impressive growth has been achieved due to remarkable advances in nutritional, genetic and reproductive management of fish and crustaceans adapted to production in captivity.

Feed safety is an essential factor to assure the productivity of those aquatic husbandries. Safety may be affected by many hazards of biological, physical or chemical origins.

The permanent increase of feed demand for farmed fish enforce the use, each time more frequent, of ingredients of vegetal origins in the formulations, as a consequence of the legal restrictions on the use of meat and bone meal for feeding farmed animals in many geographical areas, especially in the European Union [1].

The increase in the incorporation of vegetal ingredients into fish feed formula enlarges the risk of contaminations coming from that origin, namely fungi and their toxic metabolites, the mycotoxins.

The natural occurrence of such events has been noticed by many authors. Bautista et al. [2] surveyed commercial shrimp feeds in the Phillippines and reported aflatoxin B1 (AFB1) contaminations. In Egypt, Abdelhamid et al. [3] detected high levels of aflatoxins (>1000 ppb) in commercial feed used for fish production. The adverse effects in farmed fish attributed to these natural mycotoxin contaminations are not well enough elucidated.

In experimental conditions, sea bass have been exposed to prolonged oral administration of aflatoxins, for 42 consecutive days, and it was verified that this induces a significant increase in serum transaminases and alkaline phosphate activities, and a significant decrease of plasma proteins [4]. The same authors found high levels of AFB1 in fish muscles $(\approx 5 \mathrm{ppb})$ at the end of the testing period; they concluded that sea bass are vulnerable to AFB1.

Aflatoxins are secondary metabolites produced in specific ecological conditions by some strains of molds belonging to the groups of Aspergillus flavus, A. parasiticus and A. nomius [5]. Aflatoxins are recognized as inhibitors of nucleic acid synthesis. Depending on the level of exposition, these mycotoxins also decrease protein synthesis, modify lipid metabolism and mitochondrial respiratory pathway; an excessive accumulation of lipids may be noticed in the liver. In trout, prolonged exposure may induce carcinogenic effects: even with doses of $1 \mathrm{ppb}$ of aflatoxin B1 will cause liver cancer. Toxic effects of mycotoxins may differ depending on the age and fish species. Younger fish are more vulnerable; acute aflatoxicoses lesions observed are: pallid gills, impaired blood clotting, anemia, poor growth rates and reduction of growing weight. A prolonged exposure to low concentrations of AFB1 may induce liver tumors, as yellow nodules that also metastases to the kidney; with this scenario, mortality rate is increased [6].

Rainbow trout exposed through a diet containing $0.4 \mathrm{ppb}$ of AFB1 for 15 months revealed a greater than $14 \%$ probability to develop neoplasia. Feeding trout with a diet containing $20 \mathrm{ppb}$ of AFB1 for 
eight months resulted in an occurrence of $58 \%$ of liver tumors; continuing feeding for 12 months led to an increase of $83 \%$ in tumors incidence [7].

Aflatoxins also depress the immune system, making fish more susceptible to bacterial, viral or parasitic opportunist infection.

In a study conducted during 2002 [8], Nile tilapia was exposed to different concentrations of aflatoxin B1 $\left(0.25,2.5,10\right.$ and $100 \mathrm{mg} \cdot \mathrm{Kg}^{-1}$ for eight weeks). After two weeks, fish exposed to $2.5 \mathrm{mg} \cdot \mathrm{Kg}^{-1}$ or higher concentrations showed significantly reduced weight gain and hematocrit, compared with the control group. Levels of $10 \mathrm{mg} \mathrm{AFB} 1 \cdot \mathrm{Kg}^{-1}$ in the diet induced excess lipofuscin and irregularly sized hepatocellular nuclei; and diets containing $100 \mathrm{mg} \mathrm{AFB} 1 \cdot \mathrm{Kg}^{-1}$ caused weight loss and severe hepatic necrosis. However, no lesions on spleen, stomach, pyloric intestine, head kidney or heart of fish were observed. Sixty per cent of the exposed fish died within eight weeks.

Sahoo and Mukherjee [9] described reductions of total protein, globulin levels, bacterial agglutination titer, NBT and serum bactericidal activities, enhanced albumin-globulin ratio without change in albumin concentration, in fish exposed to aflatoxin B1, compared to a control group. AFB1 also proved to be immunosuppressive in rohu even at the lowest dose $\left(1.25 \mathrm{mg} \cdot \mathrm{kg}^{-1}\right)$

Sepahdari et al. [10] studied the effects of different levels of AFB1 in growth rate (SGR), weight gain and food conversion ratio (FCR) of Huso huso. Fish were fed with diets containing 0, 25, 50, 75 and $100 \mathrm{ppb}$ of AFB1 for three months. SGR was not significantly affected $(\mathrm{P}<0.05)$, however weight gain and FCR were significantly heterogeneous (diets contaminated with 75 and $100 \mathrm{ppb}$ AFB1/kg after 90 days).

Another relevant aspect related with mycotoxins in fish and crustaceans may come from the fact that hazards or their metabolites may persist in animal tissues and eventually create a risk for human health.

There is no definite correlation between mycotoxin presence in feed and the mycobiota that may be found in this matrix.

Colonization of feed by fungi is relevant when assessing the integrity of the nutrient composition of the feed and the quality of the balanced formula, especially the micro-nutrients. Fungi development enhances loss of nutrients in the feed and compromises its role in farmed fish productivity [11]. Fungi contamination may originate in the raw material feeding stuffs or be a result of a post-manufacturing cross contamination [12].

Mycobiota of feed may be conditioned by technological procedures used in feed production. Some physical treatments, including high pressure and temperature (extrusion) clearly reduce the level of fungi contamination in the finished product $[13,14]$. Organoleptic losses may also occur $[15,16]$.

The most common molds found in feed are Aspergillus, Penicillium and Fusarium genera [17-19]. Aspergilla are filamentous fungi frequently found in crops, such as cotton seed, peanut meal and corn, wheat, sunflower, soybean and even fish meal.

The aim of this preliminary study was to search and to characterize the natural mycobiota and aflatoxin contaminations in feed for farmed fish (sea bass) distributed in Portugal. 


\section{Material and Methods}

\subsection{Sampling Procedure}

Eighty-seven aliquots of feed for farmed sea bass, were randomly sampled from two Portuguese feed plants. All samples were aseptically conditioned, sent to the laboratory and tested within 24 hours. Samples were maintained at room temperature.

\subsection{Mycological Examination}

Ten grams of each sample were homogenized for $3 \mathrm{~min}$ in $90 \mathrm{~mL}\left(10^{-1}\right.$ suspension) of peptone water (Oxoid, CM 9). Ten-fold dilutions were prepared until $10^{-3}$.

One milliliter of each diluted suspension was spread onto 4 serial Petri dishes containing two different culture media: Dichloran Rose Bengal Chlortetracycline Agar (DRBCA, Diagnostic Systems-270310) and Sabourad's agar with choramphenicol (SDA, Diagnostic Systems 221825). Each Petri dish was inoculated with $0.25 \mathrm{~mL}$ in the surface of the Agar (1 mL in the 4 dishes); inoculated plates were incubated at $25{ }^{\circ} \mathrm{C}$ in the upright position for 5 days [20]. After the incubation period, colonies were counted in the DRBCA plates. Colonies developed in SDA were only considered for eventual identification purposes in case of difficulty to determine fungi genera.

Identification of each fungi colony was determined using macroscopic and microscopic morphology characterizations and taxonomic keys [21-23].

\subsection{Aflatoxins Detection and Quantification}

Search for aflatoxins was carried out using a standard method [24]. Briefly the technique may be described as follows: a $50 \mathrm{~g}$ sample was extracted with a solvent mixture of chloroform stabilized with $0.5 \%$ of ethanol $(250: 25)$ by shaking for $30 \mathrm{~min}$. After filtration through a folded filter-paper, an aliquot $(50 \mathrm{~mL})$ of the filtrate was passed through a Florisil Sep-Pak mini-column (Waters, Milford, MA, USA) previously conditioned with $10 \mathrm{~mL}$ of chloroform. The column was rinsed with $10 \mathrm{~mL}$ of chloroform, followed by $20 \mathrm{~mL}$ of methanol. The toxins AFBs (aflatoxins B1 and B2) and AFGs (aflatoxinas G1 and G2) were eluted with solvent mixture of water and acetone $(85+15)$ through $\mathrm{C}_{18}$ Sep Pak and the extract was injected in the HPLC.

The determination of AFBs and AFGs levels in samples extracts was carried out by isocratic reversephase liquid chromatography (HPLC) using a LiChrospher $100 \mathrm{RP}-18$ (5 $\mu \mathrm{m}$ column $25 \times 4.6 \mathrm{~mm}$ i.d.) EcoPack, with post column derivatization involving bromination, with pyridinum hydrobromide perbromide (PBPB) (Sigma P-3179) and with fluorescence detector. A computing integrator Merck Hitachi (Compaq Deskpro) was used; excitation and emission wavelenghts of $\lambda$ were $360 \mathrm{~nm}$ and $420 \mathrm{~nm}$. The mobile phase was a water-acetonitrile-methanol solution $(6+2+3, \mathrm{v} / \mathrm{v} / \mathrm{v})$, and the flow rates were $1.00 \mathrm{~mL} / \mathrm{min}$ for mobile phase and $0.30 \mathrm{~mL} / \mathrm{min}$ for reagent PBPB.

Recovery averages were $90.0 \%, 90.0 \%, 87.5 \%$ and $85.0 \%$ for AFB1, AFB2, AFG1 and AFG2, respectively. The detection limit of the method was $1.0 \mu \mathrm{g} \cdot \mathrm{kg}^{-1}$. 


\subsection{Standard Solutions}

Standard $\mathrm{AFB}_{1}, \mathrm{AFB} 2, \mathrm{AFG} 1$ and AFG2 (Sigma-Aldrich) working solutions were prepared using toluene/acetonitrile ( $98+2$ by volume) $(10 \mu \mathrm{g} / \mathrm{mL})$. Concentration stock solutions were determined by absorbance at $363 \mathrm{~nm}$.

\section{Results and Discussion}

Thirty-five samples of feed for farmed sea bass revealed to be contaminated with molds (Table 1).

Table 1. Number and percentage of samples positive for fungi of feed for farmed sea bass.

\begin{tabular}{cccc}
\hline Matrix & Number of Samples & Number of Positives & Percentage of Positives (\%) \\
\hline Fish feed & 87 & 35 & 40.2 \\
\hline
\end{tabular}

The total number of fungi varied from 1 to $3.3 \log _{10} \mathrm{CFU} \cdot \mathrm{g}^{-1}$ (colony forming units per gram). The only fungi genera detected were Aspergillus, Penicillium, Cladosporium and Fusarium.

Aspergillus flavus was the most frequently found mold in the 35 samples $(40.2 \%)$, presenting a mean value of $2.7 \log _{10} \mathrm{CFU} \cdot \mathrm{g}^{-1}$, ranging between 2.0 and $3.2 \log _{10} \mathrm{CFU} \cdot \mathrm{g}^{-1}$ (Table 2). The presence of $A$. flavus in some samples has been pointed to as a potential risk factor to Aflatoxins produced in the feed during storage [6].

Table 2. Number and average of mold genera account in feed for farmed sea bass.

\begin{tabular}{ccccc}
\hline Mold & $\begin{array}{c}\text { Number of } \\
\text { Positive } \\
\text { Samples }\end{array}$ & $\begin{array}{c}\text { Percentage of } \\
\text { Positives }(\%)\end{array}$ & $\begin{array}{c}\text { Average Level of } \\
\text { Contamination } \\
\left(\log _{\mathbf{1 0}} \mathbf{C F U} \cdot \mathbf{g}^{-1}\right)^{(*)}\end{array}$ & $\begin{array}{c}\text { Range } \\
\left(\log _{\mathbf{1 0}} \mathbf{C F U} \cdot \mathbf{g}^{-\mathbf{1}}\right)^{(*)}\end{array}$ \\
\hline $\begin{array}{c}\text { Aspergillus } \\
\text { flavus }\end{array}$ & 35 & 40.2 & 2.7 & $2-3.1$ \\
$\begin{array}{c}\text { Aspergillus niger } \\
\text { Aspergillus }\end{array}$ & 34 & 39.1 & 2.2 & $1-2.6$ \\
$\begin{array}{c}\text { glaucus } \\
\text { Penicillium spp. }\end{array}$ & 26 & 29.9 & 1.9 & $1-2.3$ \\
$\begin{array}{c}\text { Cladosporium } \\
\text { spp. }\end{array}$ & 25 & 28.7 & 2.0 & $2-2.8$ \\
Fusarium spp. & 22 & 28.7 & 1.9 & $2-3.3$ \\
\hline
\end{tabular}

Note: (*) CFU-colony forming units per $\mathrm{g}$.

Aspergillus niger was found in 34 samples (39.1\%) at a mean value of $2.2 \log _{10} \mathrm{CFU} \cdot \mathrm{g}^{-1}$, ranging from 1 to $2.7 \log _{10} \mathrm{CFU} \cdot \mathrm{g}^{-1}$. Aspergillus glaucus was found in 26 samples (29.9\%), showing colonies levels ranging from 1 to $2.4 \log _{10} \mathrm{CFU} \cdot \mathrm{g}^{-1}$.

Penicillium spp. and Cladosporium spp. were both found in 25 samples (28.7\%) in levels that ranged from 2.0 to $2.8 \log _{10} \mathrm{CFU} \cdot \mathrm{g}^{-1}$ and 2.0 to $3.3 \log _{10} \mathrm{CFU} \cdot \mathrm{g}^{-1}$, respectively. Fusarium spp. were found in 22 samples $\left(25.3 \%\right.$ ), showing levels of contamination that varied from 1 to $2.3 \log _{10} \mathrm{CFU} \cdot \mathrm{g}^{-1}$ (Table 2). 
This study identified and enumerated spoilage fungi in less than half of the samples of feed for farmed sea bass, but their toxigenic competence were not determined.

Jakić-Dimić et al. [25] tested 43 samples of feed stuffs used for feed fish production and found high levels of mold contamination (Aspergillus, Penicillium, Fusarium and Rhisopus). The highest rank of contamination was registered in corn samples.

Feed stuffs used as ingredients for feed production have been found to be frequently contaminated with fungi in Portugal, as described in many published studies. Results of surveys published in 2007, in crops and feeds for livestock, showed high numbers of positive samples, with levels of contamination that ranged from $1.7 \log _{10}$ to $4.7 \log _{10} \mathrm{CFU} \cdot \mathrm{g}^{-1}$ [26-28]. These data were considered as inspiration to realize the present study, but results revealed to be very different.

Others results presented by different authors [19] concluded that the levels and frequency of fungi contamination are generically decreasing, taking in consideration the results of longitudinal surveys performed in the last ten years in Portugal.

Dalcero et al. [29] characterized the mycobiota of 130 samples of poultry feed; those samples were contaminated with levels that ranged from 3 to $4.9 \log _{10} \mathrm{CFU} \cdot \mathrm{g}^{-1}$ for Aspergillus spp and 3.0 to $5.3 \log _{10} \mathrm{CFU} \cdot \mathrm{g}^{-1}$ for Penicilium spp. These results were in line with those obtained in 2001, screening feed for livestock in Portugal [19].

In 2010, a similar study performed by Saleemi et al. [30] of 190 samples, showed a lower fungi contamination.

The other aim of this study was to determine aflatoxins in the analyzed samples. Although the aflatoxins recovery comply with the acceptance limits (98.0, 99.0 and 103.0\%), the results show that those mycotoxins were not present in any of the 87 samples.

Aflatoxins are also common and naturally found in feed stuffs of vegetal origin used as ingredients for feed production. Some authors consider the use of crop of vegetal origin as a rising risk factor for the occurrence of mycotoxicosis in farmed fish and crustaceans [7].

Altug and Beklevik (2003) [31] found aflatoxins in many of the 153 samples of fish feed during a three years study (1998 to 2000). In 85 of these positive samples, the levels of contaminations were over $21 \mu \mathrm{g} \cdot \mathrm{kg}^{-1}$.

Bernardo et al. (2009) [32] conducted a study with 27 samples of feed for fish for aflatoxins detection, and found two positive results, with levels of 5 and $6 \mu \mathrm{g} \cdot \mathrm{kg}^{-1}$.

Jakić-Dimić et al. (2005) [25], analyzed 43 samples of raw materials (corn, wheat and barley), used as ingredients for fish feed and found levels of aflatoxin B1 contamination ranging from 5 to $40 \mu \mathrm{g} \cdot \mathrm{kg}^{-1}$.

To assess mycobiota and its evolution on the food chain, it is essential to have a tool to manage any intensive or semi-intensive animal production systems. This begins in cultural practices of cereals in the field as well as harvest, transport and storage conditions. Physical, chemical or biological treatments for decontamination are a controversial issue, although some feed additives, namely some authorized adsorbents (Regulation (EC) no 386/2009) [26], may have some influence on the reduction of mycotoxin absorption at the intestine level; binding to mycotoxins decrease bioavailability and indirectly reduce mycotoxin effects. This question is not adequately solved in regulatory terms. 


\section{Conclusions}

Screening feed for farmed fish for mold contaminations and its toxins is a relevant strategy to assure the safety conditions of these feeds. The presence and the level of potentially toxigenic fungi in fish feed may be relevant to enhance safety guarantees to aquaculture productions. The progressive use of vegetal ingredients in fish feed is an inherent risk for molds and mycotoxin contaminations of an inestimable production factor.

Results found in the present study may be an expression of an adequate control system to implement in feed plants that produce this kind of feed. However, the specific group of molds that have been found, namely A. flavus, Penicillia and Fusaria, can represent a safety risk if storage conditions, after manufacturing, are compatible with mold growth.

\section{Reference}

1. FAO; WHO. Joint FAO/WHOFoods Standards Programme. Code of Practice for Good Animal Feeding. Technical Report for Codex Alimentarius Commission, Rome, Italy, 2004.

2. Bautista, M.N.; Lavilla-Pitogo, C.R.; Subosa, P.F.; Begino, E.T. Aflatoxin B1 contamination of shrimp feed and its effect on grow and hepatopancreas and pre-adult Penaeus monodom. J. Sci. Food Agr. 1994, 65, 5-11.

3. Abdelhamid, A.M.; Khalil F.F.; Ragab, M.A. Problem of Mycotoxins in fish production. Egypt. J. Nutr. Feeds 1998, 1, 63-71.

4. El Sayed, Y.S.; Khalil, R.H. Toxicity, biochemical effects and residue of aflatoxin B1, in marine water-reared sea bass (Diacentrarchus labrax L.). Food Chem. Toxicol. 2009, 47, 1606-1609.

5. Miliţă, N.M.; Mihăescu, G.; Chifiriuc, C. Aflatoxins-Health risk factors. Bacteriol Virusol Parazitol Epidemiol. 2010, 55, 19-24.

6. Russo, J.R.; Yanong, R.P.E. Molds in Fish Feeds and Aflatoxicosis; Institute of Food and Agriculture Sciences, University of Florida: Gainesville, FL, USA, 2010.

7. Spring, P.; Fegan, D.F. Mycotoxins-A Rising Threat to Aquaculture; Alltech Inc.: Brentwood, TN, USA, 2010.

8. Tuan, N.A.; Grizzle, J.M.; Lovell, R.T.; Manning, B.B.; Rottinghaus, G.E. Growth and hepatic lesions of Nile tilapia (Oreochromis niloticus) fed diets containing aflatoxin B1. Aquaculture 2002, 212, 311-319.

9. Sahoo, P.K.; Mukherjee, S.C. Immunosuppressive effects of aflatoxin B1 in Indian major carp (Laboe rohita). Microbiol. Infectious Dis. 2001, 24, 143-149.

10. Sepahdari, A.; Ebrahimzadeh Mosavi, H.A.; Sharifpour, I.; Khosravi, A.; Motallebi, A.A.; Mohseni, M.; Kakoolaki, S.; Pourali, H.R.; Hallajian, A. Effects of different levels of AFB1 on survival rate and growth factors of Beluga (Huso huso). Iran. J. Fish. Sci. 2010, 9, 141-150.

11. Zmyslowska, I.; Lewandowska, D. The effect of Storage Temperatures on the Microbiological quality of Fish Feeds. Pol. J. Environ. Stud. 2000, 3, 223-226.

12. Magan, N.; Aldred, D. Post-harvest control strategies: Minimizing mycotoxins in the food chain. Int. J. Food Microbiol. 2007, 119, 131-139. 
13. Hashimoto, E.H.; Santos, M.A.; Ono, E.Y.S.; Hayashi, C.; Bracarense, A.P.F.; Hirooka, E.Y. Bromatology and fumonisin and aflatoxin contamination contaminationin aquaculture feed of the region of Londrina, State of Paraná, Brazil. Semina Ciencias Agrarias 2003, 24, 123-132.

14. Suárez, O. Manejo de los granos en las fábricas de alimentos. Industria Avícola 1999, 10, 18-21.

15. Joseph, L. Toxigenic Fungi from Poultry Feed and Litter. Poultry Sci. 1971, 51, 309-313.

16. Cole, R.; Cox, R. Handbook of Toxic Fungal Metabolites; Academic Press: New York, NY, USA, 1981; pp. 1-500.

17. Abarca, M.L.; Bragulat, M.R.; Castellá, G.; Cabãnes, F.J. Ochratoxin A production by strains of Aspergillus niger var niger. Appl. Environ. Microbiol. 1994, 60, 2650-2652.

18. Joosten, H.L.J.; Goetz, J.; Pittet, A.; Hellenberg, M.; Bucheli, P. Production of ochratoxin A by Aspergillus carbonarius on coffee cherries. Intern. J. Food Microbiol 2001, 65, 39-44.

19. Martins, L.M.; Martins, H.M. Moulds and aflatoxins contamination in swine, bovines and poultry feeds in Portugal. In COST-European Cooperation in the Field of Scientific and Technical Research. Agriculture and Biotechnology. Occurrence of Toxigenic Fungi and Mycotoxins in Plants, Food and Feed in Europe; Logrieco, A., Ed.; European Commission: Bari, Italy, 2001; pp. 131-146

20. King, A.D., Jr.; Pitt, J.I.; Beuchat, L.R.; Corry, J.E.L. Methods for the Mycological Examination of Food; King, A.D., Jr., Pitt, J.I., Beuchat, L.R., Corry, J.E.L., Eds.; Springer: New York, NY, USA, 1984.

21. Pitt, J.J.; Hocking, A.D. Fungi and Food Spoilage; Sydney Academic Press: Sydney, Australia, 1985.

22. Raper, K.B.; Fennel, D.I. The Genus Aspergillus; The Williams and Wilkinson Co.: Baltimore, MD, USA, 1965.

23. Domsch, K.; Gams, W. Compedium of Soil Fungi; Academic Press: London, UK, 1980; p. 566.

24. Van Egmond, H.P.; Heisterkamp, S.H.; Paulsch, W.E. EC-collaborative study on the determination of aflatoxin B1 in animal feeding stuffs. Food Addit. Contam. 1991, 8, 17-29.

25. Jakić-Dimić, D.; Jeremić, S.; Nešić, K.; Radosavljević, V. The influence of mycotoxins in food on fish health status. Proc. Nat. Sci. 2005, 109, 73-79.

26. Almeida, I; Marques, M.; Torrado, E.; Martins, H.M. Study Of Mycobiota in Corn-Based Food Products, Current Research topic in Applied Microbiology and Microbial Biotechnology. In Proceedings of the II International Conference on Environmental Industrial and Applied Microbiology, Seville, Spain, 28 November-1 December 2007.

27. Almeida, I; Marques, M.; Torrado, E.; Martins, H.M. Occurrence of mycobiota in swine feed. Current Research topic in Applied Microbiology and Microbial Biotechnology. In Proceedings of the II International Conference On Enviornmental Industrial And Applied Microbiology, Seville, Spain, 28 November-1 December 2007.

28. Almeida, I.F.; Marques, M.F.; Covita, R.M.; Martins, H.M. Contribution to the fungal characterization of poultry feed. Current Research topic in Applied Microbiology and Microbial Biotechnology. In Proceedings of the II International Conference on Enviornmental Industrial And Applied Microbiology, Seville, Spain, 28 November-1 December 2007.

29. Dalcero, A.; Magnoli, C.S.; Palacios, G.; Reynoso, M. Mycoflora and incidence of aflatoxin B1, zearalenone and deoxinivalenol in poultry feeds in Argentina. Mycopathologia 1998, 135, 179-184. 
30. Salleemi, M.K.; Khan, M.; Khan, A.; Javed, I. Mycoflora of poultry feeds and Mycotoxins producing potential of Aspergillus species. Pak. J. bot. 2010, 42, 427-434.

31. Altug, G.; Beklevik, G. Level of aflatoxin in some fish feeds from fish farming processes, feed factories and imported feeds. Turk. J. Vet. Anim. Sci. 2003, 27, 1247-1252.

32. Regulation (EC) No 1831/2003 of the European Parliament and the Council of 22 September 2003 on additives for use in animal nutrition. Available online: http://irmm.jrc.ec.europa.eu/ SiteCollectionDocuments/EC-1831-2003.pdf (accessed on 24 February 2011).

(C) 2011 by the authors; licensee MDPI, Basel, Switzerland. This article is an open access article distributed under the terms and conditions of the Creative Commons Attribution license (http://creativecommons.org/licenses/by/3.0/). 